\title{
USOS NO DOCUMENTADOS DE AGUAS EN LA LEGISLACION CHILENA
}

\author{
PATRICIO ARIAS HARDOY \\ Abogado
}

Resulta interesante pronunciarse sobre un punto de derecho tan relevante en materia de aguas, como es el de los usos no documentados del recurso, considerando que estamos en presencia de una legislación muy nueva, cuyo propósito más relevante es el de normalizar el uso de las aguas en Chile.

El intento declarado parece ser mejor que el resultado, porque han surgido numerosas interpretaciones contradictorias respecto a muchos temas trascendentes y además la propia autoridad ha enviado tres proyectos abortados de modificación del Código desde 1992, sin perjuicio de otras modificaciones menores en los años 1984 y 1987.

Mi exposición intentará analizar las normas aplicables a los usos no formalizados de las aguas, que a pesar de haber sido el objeto de muchos encuentros académicos y sobre el cual algunos especialistas han escrito profusamente, no existe consenso sobre sus fundamentos, su legitimación y tampoco sobre la interpretación de las normas que los rigen.

Los usos de aguas son considerados legítimos por las normas, si concurren algunas de estas circunstancias:

1. Si se ha adquirido el respectivo derecho de aprovechamiento de aguas por acto de autoridad.

2. Si el uso es reconocido en calidad de derecho de aprovechamiento de aguas, por el solo ministerio de la ley; o
3. Si el uso está legitimado por la ley, protegido y amparado por ella, y en algunos casos, susceptible de reconocerse en calidad de derecho de aprovechamiento de aguas, mediante sentencia judicial.

Nos referiremos a los usos no documentados de aguas que se consideran en los puntos 2 y 3 indicados precedentemente.

\section{USOS RECONOCIDOS COMO DERECHOS DE APROVECHAMIENTO POR EL SOLO MINISTERIO DE LA LEY}

Los usos reconocidos como derechos de aprovechamiento por el solo ministerio de la ley están expresamente señalados en ella, a modo ejemplar: los que corresponden a vertientes que nacen, corren y mueren dentro de una misma heredad, los de las aguas de lagos menores, los ligados a la exploración, explotación y beneficio de pertenencias mineras; los de las comunidades agrícolas, los de los indígenas, los usos domésticos $\mathrm{y}$, por último, los contemplados en los artículos 310 a 313 del Código de Aguas.

Estos derechos por su naturaleza, utilización, posición física y otros que los delimitan y enmarcan, tienen las características propias de su definición. Efectivamente, por ejemplo, los derechos a las aguas de lagos menores son consuntivos, permanentes y continuos en la medida en que físicamente sea posible usar y gozar de sus aguas en esa forma. No existe fundamento para negar al propietario de las riberas el uso del agua con esas modalidades. 
Igualmente, el titular de una pertenencia minera usa toda el agua que halle en sus labores, con las mismas características, siempre que sea necesaria para la exploración, explotación o beneficio del mineral.

Estos usos están amparados por la ley con esas modalidades y no resulta extraño a nuestra apreciación del derecho de aguas, que se hayan recogido estos casos en la legislación actual, pues tienen precedentes inmemoriales.

Sin embargo, estos derechos no están inscritos en los registros de propiedad de aguas respectivos, ni tampoco están explícitas tales características de consuntividad, permanencia y continuidad, y puede ser que no se reúnan tales elementos en su ejercicio.

Así, las aguas reservadas a los indígenas tendrán preferentemente un uso agrícola y ello implica que no necesariamente van a tener el carácter de continuidad que se supone en un derecho reconocido por el solo ministerio de la ley. Solamente las aguas se usarán en temporada de riego y con ello limitarán, durante todo el año, el uso de ellas abajo de sus captaciones.

Por ello, esas características podrían entrabar el otorgamiento de otros derechos sobre esas aguas y afectar la disponibilidad del recurso en los balances hídricos.

El constituyente y el legislador han establecido un ordenamiento que pretende dos finalidades fundamentales:

1. Que todas las aguas terrestres en Chile tengan un titular que las use y goce; $y$

2. Que ese uso y goce, que es un derecho de aprovechamiento, esté debidamente inscrito.

De esta forma todas las aguas, subterráneas y superficiales, serían objeto de derecho perfectamente identificable, con la debida certeza, publicidad, seguridad, y protegido legal y constitucionalmente.

La concreción de ese propósito, respecto a los derechos de aprovechamiento de aguas reconocidos por el solo ministerio de la ley, es factible realizarla judicialmente por la vía de solicitar al juez, de acuerdo a lo dispuesto en los artículos 177 y siguientes, y $114 \mathrm{~N}^{\circ} 7 \mathrm{del}$ Código de Aguas, que reconozca la existencia del derecho.
El juez necesariamente debería solicitar de la Dirección General de Aguas que informe al respecto, a fin de que se pronuncie sobre las características del derecho, el cual tiene que contemplar todos los elementos esenciales que caracterizan los derechos de aprovechamiento de aguas constituidos por la autoridad y señalados en el artículo 149 del Código de Aguas. Dicha disposición señala los requisitos que debe contener la resolución en cuya virtud se constituye el derecho de aprovechamiento de aguas. En síntesis, el nombre del álveo, la comuna en que se encuentra la captación de aguas subterráneas, la cantidad de agua, el punto preciso de captación, si el derecho es consuntivo o no consuntivo, de ejercicio permanente o eventual, continuo o discontinuo o alternado con otras personas.

Especial relevancia adquiere en estos casos el $\mathrm{N}^{\mathrm{o}} 7$ del artículo 149 del Código de Aguas, pues allí se señala que deben mencionarse las especificaciones técnicas relacionadas con la naturaleza especial del respectivo derecho y las modalidades que lo afecten, lo que resulta enteramente aplicable a la descripción que deba hacer el juez respecto a estos derechos.

Sólo a modo ejemplar, señalaremos que el minero sólo puede disponer del agua mientras sea titular de su pertenencia y en la medida necesaria para sus fines, que las aguas reservadas para usos domésticos sólo son utilizables en ellos y en ningún caso pueden extenderse a otros indirectos, que las aguas lluvias sólo pueden usarse al interior de los predios, etc.

Las respectivas inscripciones deberán también contemplar estas limitaciones, lo que normalmente no se hace.

\section{USOS LEGITIMADOS POR LA LEY, PROTEGIDOS \\ Y AMPARADOS POR ELLA, SUSCEPTIBLES DE FORMALIZARSE}

Las normas que regulan la regularización están contenidas en los artículos $1^{\circ}, 2^{\circ}$ y $5^{\circ}$ transitorios del Código de Aguas.

Los artículos $1^{\circ}$ y $5^{\circ}$ transitorios contemplan situaciones de regularización que prácticamente son una actualización de inscripciones, pues se trata de derechos inscritos o reconocidos de los predios expropiados.

Los usos inmemoriales no documentados, que son susceptibles de regularizarse de acuer- 
do al artículo $2^{\circ}$ transitorio, a nuestro entender, no son derechos de aprovechamiento de aguas no inscritos, sino que simplemente usos legítimos, protegidos y amparados por la ley, lo que pasaremos a analizar y esperamos probar.

\section{Fundamentos legales de la formalización de los usos de aguas}

El objetivo central y obvio del artículo $2^{\circ}$ transitorio del Código de Aguas, es la normalización del régimen de aguas en Chile, mediante su asimilación al que rige la posesión inscrita de los bienes raíces. Se trata que todas las aguas utilizables del país estén inscritas y que se reconozcan, con la debida certeza jurídica, a los titulares de derechos de aprovechamiento de ellas.

Este propósito del legislador se corrobora en el artículo 121 del Código de Aguas que señala:

"A los derechos de aprovechamiento inscritos en los Registros de Aguas de los Conservadores de Bienes Raices, se les aplicarán todas las disposiciones que rijan la propiedad raíz inscrita, en cuanto no hayan sido modificadas por el presente Código".

Sin embargo, en Chile existe un porcentaje importante de aguas que se utilizan en forma inmemorial, sin perjuicio de terceros, en forma consuetudinaria y sin violencia ni clandestinidad y que no están inscritas.

Atendida esta realidad, el legislador dictó el Decreto Ley $\mathrm{N}^{\circ}$ 2.603, publicado en el Diario Oficial $\mathrm{N}^{\circ} 30.346$, de 23 de abril de 1979, para los efectos de "reconocer" dichos usos de aguas, estableciendo para ellos una clara y determinante presunción de legitimidad y juridicidad, en la siguiente forma:

Señala el considerando de dicha norma legal:

"Considerando: que es necesidad nacional iniciar el proceso de normalización de todo cuanto se relaciona con las aguas y sus diferentes formas de aprovechamiento..."

Y a continuación el Decreto Ley prescribe:

"Artículo $7^{\circ}$. Se presumirá dueño del derecho de aprovechamiento a quien lo sea del inmueble que se encuentra actualmente utilizando dichos derechos.

En caso de no ser aplicable la norma precedente, se presumirá que es titular del derecho de aprovechamiento quien se encuentre actualmente haciendo uso efectivo del agua."

De esta forma, el legislador reconoció como presuntos titulares de derechos a los usuarios de aguas y confirió legitimidad a los usos que se efectuaren cumpliendo los requisitos legales.

Concordantemente con lo anterior, el artículo $19 \mathrm{~N}^{\mathrm{o}} 24$ de la Constitución, distinguió entre derechos "constituidos" y derechos "reconocidos" al asegurar la propiedad de tales derechos en la siguiente forma:

"Los derechos de los particulares sobre las aguas, reconocidos o constituidos en conformidad a la ley, otorgarán a sus titulares la propiedad sobre ellos".

Los derechos "reconocidos", en conformidad a la ley, son, entre otros, aquellos a los que se refiere el artículo $7^{\circ}$ del Decreto Ley $\mathrm{N}^{\circ}$ 2.603, de 1979.

A continuación, el legislador dio coherencia a su propósito de legitimación y saneamiento de usos de aguas, estableciendo un procedimiento de formalización en el artículo $2^{\circ}$. transitorio del Código de Aguas, que permite regularizar derechos inscritos o no inscritos que estén siendo utilizados por personas distintas de sus titulares, con los requisitos que allí se establecen.

Finalmente el legislador, al igual que respecto a los derechos constituidos por la autoridad, ordenó en lo relativo a los derechos reconocidos en conformidad a la ley, en el $\mathrm{N}^{\circ} 7 \mathrm{del}$ artículo 114 del Código de Aguas, que deberán inscribirse en el Registro de Propiedad de Aguas:

“7. Las resoluciones judiciales ejecutoriadas que reconozcan la existencia de un derecho de aprovechamiento".

De esta manera se establecen las normas que permiten inscribir usos de aguas y concretar la intención del legislador en cuanto a normalizar el uso de las aguas en el país. 
Analizaremos a continuación dos puntos que nos parecen ejemplares, en cuanto a la falta de uniformidad de criterios respecto a materias relevantes del derecho de aguas:

\section{LOS USOS AMPARADOS POR LA PRESUNCIÓN DE TITULARIDAD DEL DECRETO LEY N ${ }^{\circ} 2.603$ DE 1979, NO CONSTITUYEN AL USUARIO EN TITULAR DE DERECHO DE APROVECHAMIENTO DE AGUAS}

Los usuarios de aguas, en cuyo favor existe una presunción legal de ser titulares de derechos de aprovechamiento, están habilitados por la ley para regularizar sus derechos, es decir para inscribirlos, mediante la interposicion de la acción judicial correspondiente.

Sin embargo esta presunción de titularidad no es suficiente para considerar que el que esté haciendo uso del agua sea propietario de un derecho de aprovechamiento de aguas.

Ello por una razón de texto y por una razón práctica.

El texto del inciso final del $\mathrm{N}^{\circ} 24$ del artículo 19 de la Constitución Política, asegura a las personas la propiedad sobre los derechos de aprovechamiento de aguas siempre que estén reconocidos o constituidos "en conformidad a la ley".

El reconocimiento de los derechos de aprovechamiento de aguas se hace en conformidad a la ley, sólo cuando se ha obtenido a favor del regularizador una sentencia judicial que ha reconocido su derecho y dicha sentencia esté ejecutoriada, como lo señala expresamente el $\mathrm{N}^{\circ} 7$ del artículo 114 del Código de Aguas.

Consideramos que antes de la formalización acabada de la sentencia que reconoce la existencia del derecho de aprovechamiento de aguas, no existe en el patrimonio del usuario del recurso un derecho de aprovechamiento, tal como lo define el artículo $6^{\circ}$. del Código de Aguas.

El mero uso del agua no otorga un derecho real. Para que se reconozca la existencia del derecho es necesario cumplir y acreditar en sede judicial el cumplimiento de todos los requisitos establecidos en la ley.

Antes de que exista una decisión jurisdiccional, el usuario de aguas está protegido por una presunción que le permite defender dicha utilización ante un atropello arbitrario, me- diante el amparo judicial de aguas, pero ello no le confiere titularidad alguna, al punto que el legítimo propietario de derecho de aprovechamiento obtendrá sentencia a su favor en dicho amparo, si logra acreditar su titularidad.

No es necesario acreditar ser titular de derechos de aprovechamiento para inscribir derechos mediante el procedimiento contemplado en el artículo $2^{\circ}$ transitorio del Código de Aguas.

Se ha sostenido en estrados judiciales que en el procedimiento de regularización es necesario que el actor acredite ser dueño de derechos de aprovechamiento de aguas, porque de otra forma se estaría en presencia de un hecho que se transforma en derecho.

Hasta la fecha no había existido un pronunciamiento de la Excma. Corte Suprema, que permitiera definir las opiniones que surgen a este respecto.

Ahora, con fecha $1^{\circ}$ de octubre de 1998, nuestro más alto tribunal ha dirimido, esperamos definitivamente, este punto, en un fallo recaído en un recurso de casación en la forma deducido por las opositoras, en el proceso de regularización de derechos de aprovechamiento de aguas de Codelco Chile, División Andina con la Junta de Vigilancia de la Primera Sección del río Aconcagua, Primera Sección y las Hidroeléctricas Guardia Vieja y Aconcagua.

En dicho fallo se reconoce que la presunción de titularidad, para quien esté usando el recurso, establecido en el citado D.L. $\mathrm{N}^{\circ} 2.603$ de 1979, y en presencia de los requisitos establecidos en el artículo $2^{\circ}$ transitorio del Código de Aguas, dan mérito para inscribir un derecho de aprovechamiento de aguas, el que preexistiría sobre la base de las disposiciones citadas y a la consagración constitucional de los derechos reconocidos en conformidad a la ley.

La buena doctrina ha imperado, porque de esta manera se concreta el deseo del legislador de que estén inscritas todas las aguas del país y que se reconozcan los usos legítimos con las condiciones que estableció el legislador.

No resulta así valida la interpretación contraria, en orden a sostener que es necesario acreditar derechos de aprovechamiento de aguas para regularizar, sino que simplemente se reconoce legitimidad a los usos de aguas que cumplen determinados requisitos y que el legislador, y ahora la jurisprudencia, 
permiten inscribir en los Registros de Propiedad de Aguas para su adquisición plena por prescripción.

Se ha producido, a nuestro juicio, un avance en satisfacer la necesidad de normalizar, dar certeza jurídica y obtener en definitiva que todos los derechos de aprovechamiento sobre todas las aguas estén debidamente inscritos y evitar, de ese modo, las disputas que han hecho historia por el recurso en Chile. 